\title{
Feeding difficulties in infants with unrepaired cleft lip and palate and HIV-exposure
}

\author{
Erantia E Visser, Esedra E Krüger, Aletta Margaretha AM Kritzinger
}

Department of Speech-Language Pathology and Audiology, Faculty of Humanities, University of Pretoria Private Bag X20, Hatfield 0028.

\section{Emails:}

Erantia E Visser: erantiav@gmail.com; Esedra E Krüger: esedra.kruger@up.ac.za; Aletta Margaretha AM Kritzinger: alta.kritzinger@up.ac.za

\begin{abstract}
Background: There is limited description of the feeding characteristics of infants with unrepaired cleft lip and palate, exposed to HIV, but not necessarily infected.

Objective: To compare the feeding characteristics of infants with unrepaired cleft lip and palate and HIV-exposure, to infants with unrepaired cleft lip and palate only.

Method: A two-group comparative design with a validated measure, the Neonatal Feeding Assessment Scale was used. The effectiveness of oral feeding skills were included as objective measure. Twelve participants with unrepaired cleft lip and palate and HIV-exposure and 13 with unrepaired cleft lip and palate were matched according to cleft type and use of feeding obturator. There were no differences between the groups for mean age, birth weight and gestation. Participants were between two and 89 days old, bottle fed, and had no syndrome/co-occurring disorder.

Results: Nine (75\%) participants in the research group and only two (15.38\%) in the control grouppresented with the likelihood of oropharyngeal dysphagia. Apart from feeding difficulties as a result of structural impairment, the research group showed symptoms of neurological involvement.

Conclusion: The research group presented with distinctive symptoms of oropharyngeal dysphagia. More studies using different measuring tools are required to strengthen the evidence.

Keywords: HIV-exposed infants, unrepaired cleft lip and palate, feeding difficulties.

DOI: https://dx.doi.org/10.4314/ahs.v18i4.31

Cite as: Visser EE, Krüger EE, Kritzinger AMAM. Feeding difficulties in infants with unrepaired cleft lip and palate and HIV -exposure. Afri Health Sci. 2018;18(4): 1098-1108. https:// dx.doi.org/10.4314/abs.v18i4.31
\end{abstract}

\section{Introduction}

Prior to the availability of anti-retroviral treatment (ART), infants born from HIV-positive mothers were infected

\section{Corresponding author:}

Erantia E Visser, Unit 4 Reading Hills

65 Eeuwfees street

Alberton, 1449

Contact number: +2768180315

Email address: erantiav@gmail.com with $\mathrm{HIV}^{1}$. Since the prevention of mother-to-child-transmission (PMTCT) programme has been gaining success in South Africa, the percentage of HIV-positive pregnant women receiving ART, has increased from 93\% in 2010 to $>95 \%$ in $2016^{2}$. Therefore, ART has become accessible to more pregnant women, and its use during pregnancy was found to be safe in trials to date ${ }^{3}$. In 2016 the World Health Organization (WHO) established new guidelines for infant feeding and PMTCT in infants born to HIV-positive mothers ${ }^{4,5}$. Guidelines include reducing the availability of free infant formula; lifelong use of ART for all pregnant or breastfeeding HIV-positive women, regardless of the $\mathrm{CD}^{+}{ }^{+}$cell count ${ }^{4,5}$. HIV-exposed (HIV-E) 
infants should receive dual prophylaxis with daily Zidovudine (ZDV) and Nevirapine (NVP) for the first six weeks of life, whether breastfed or formula fed, and a 12-week extended use of NVP alone or dual treatment (ZDV/NVP), to ensure PMTCT during breastfeeding 5 . Guidelines state that mothers on ARTs may breastfeed exclusively for the first six months, introduce appropriate complimentary feeds and may continue breastfeeding for up to 24 months or longer ${ }^{4}$.

With the new ART-era, increased numbers of women of childbearing age are accessing combined antiretroviral therapy (cART) and conceive on efavirenz-based cART ${ }^{6}$, resulting in many infants being exposed to HIV, but not necessarily infected ${ }^{7,8}$. To date no association has been found between in-utero exposure to any ART and neurodevelopmental outcomes, in early infancy and up to the age of two years ${ }^{9}$. However, subtle delays have been found in cognitive and motor functioning as well as language and behaviour in children three to five years of age $^{10}$. Although prenatal exposure to any form of ART has not yet been linked to cleft lip and palate (CLP), infants born with the condition may have been exposed to a double teratogenic effect, which includes the HI-virus and ART medication ${ }^{11}$. As two separate groups, feeding difficulties of infants with unrepaired CLP, and infants with HIV infection are described in great detail in the literature. There appears to be no reports on feeding characteristics of infants with unrepaired CLP and HIV-E, receiving ART.

The type of cleft determines the severity of feeding difficulties before repair ${ }^{12}$. Isolated cleft lip generally does not cause significant feeding difficulties ${ }^{12,13}$. Infants with clefts of the primary palate, including the lip and alveolus, might have difficulty to obtain a lip seal and nipple compression ${ }^{13}$. Infants with uni- or bilateral CLP or clefts of the hard and soft palate have significant feeding difficulties due to the inability to generate sufficient negative intraoral pressure during sucking, leading to nasal regurgitation and excessive air intake during feeding ${ }^{14}$. Breastfeeding in infants with unrepaired CLP may not be possible, and modified nipples and feeding obturators may be necessary for successful feeding ${ }^{14}$.

Specific feeding difficulties associated with HIV-infected infants are also well-known, such as problems with oral intake due to odynophagia, aspiration, lengthy feeding sessions, refusal to feed, failure to thrive and weak/discoordinated tongue movements ${ }^{15}$. Although all swallowing phases might be affected in infants with HIV, the oral phase appears to be primarily affected in infants infected with HIV and infants with unrepaired CLP ${ }^{12,15}$.

Feeding methods used with HIV-exposed infants remain challenging due to the confounding effects of ART exposure and the resulting effects on the fetus ${ }^{7,16}$. Infantsexposed to HIV and ART are at risk of low birth weight and preterm birth $(\mathrm{LBW} / \mathrm{PTB})^{17}$. Breastfeeding readiness may be compromised at birth and later introduction of breastfeeding is often unsuccessful. HIV-exposed infants may continue to experience effects of HIV in their families, due to psychosocial and economical challenges ${ }^{18}$. Therefore, the aim of this study was to compare the feeding characteristics of very young infants with unrepaired CLP and HIV-E, to infants with CLP only. Results from this study may isolate specific feeding characteristics associated with HIV-E in CLP infants. The information may assist speech-language therapists and other healthcare professionals to anticipate feeding support for this unique population, resulting in early identification of feeding difficulties, and the development of strategies to assist parents effectively.

\section{Methods}

\section{Setting and participants}

The study was conducted at the Facial Cleft Deformities Clinic (FCDC) of an academic dental hospital in Pretoria, South Africa. The clinic has an established CLP treatment protocol from birth to eighteen years, during which patients are followed-up by a multidisciplinary team ${ }^{19}$. A unilateral or bilateral cleft lip, alveolus, and clefts of the soft palate are repaired at five months and an isolated soft palate cleft or only a soft palate and hard palate cleft, is first operated on at seven months ${ }^{20}$. Non-probability purposive sampling was used to select $(n=25)$ participants. The study was pre-experimental and exploratory in nature using a two-group design. Pre-experimental research is conducted to form a tentative hypothesis that should be followed up with more controlled studies ${ }^{21}$. The study therefore attempted to confirm an alternative hypothesis, which proposed that there was a statistically significant difference between the feeding of participants with unrepaired CLP and HIV-E, compared to participants with unrepaired CLP only. The design allowed for the com- 
parison of the feeding characteristics of infants with unrepaired CLP and HIV-E $(n=12)$ to infants with CLP only and HIV-unexposed $(n=13)$. All parents of infants with unrepaired CLP, who were bottle fed and $\leq 3$ months old were asked to participate. Infants using tube, cup, or syringe feeding, and with syndromes or co-occurring disorders, were excluded. Close matching for cleft type and use of feeding obturators between study groups were achieved(Table 1).

\section{Table 1 Matching of study groups}

\begin{tabular}{|c|c|c|c|c|c|}
\hline \multicolumn{3}{|c|}{$\begin{array}{c}\text { Research Group (RG) } \\
\text { Infants with unrepaired CLP and HIV-E }(n=12)\end{array}$} & \multicolumn{3}{|c|}{$\begin{array}{c}\text { Control Group (CG) } \\
\text { Infants with unrepaired CLP }(n=13)\end{array}$} \\
\hline $\begin{array}{l}\text { Participant } \\
\text { number }\end{array}$ & Cleft type & $\begin{array}{c}\text { Feeding } \\
\text { obturator }\end{array}$ & $\begin{array}{l}\text { Participant } \\
\text { number }\end{array}$ & Cleft type & $\begin{array}{l}\text { Feeding } \\
\text { obturator }\end{array}$ \\
\hline R9 & $\begin{array}{l}\text { Unilateral cleft lip } \\
\text { and alveolar ridge }\end{array}$ & $\mathrm{x}$ & $\mathrm{C} 18$ & $\begin{array}{l}\text { Unilateral cleft lip } \\
\text { and alveolar ridge }\end{array}$ & $\mathrm{x}$ \\
\hline R6 & Unilateral CLP & $\mathrm{x}$ & $\mathrm{C} 5$ & Unilateral CLP & V \\
\hline $\mathrm{R} 8$ & Unilateral CLP & v & $\mathrm{C} 14$ & Unilateral CLP & v \\
\hline \multirow[t]{2}{*}{$\mathrm{R} 11$} & \multirow[t]{2}{*}{ Unilateral CLP } & \multirow[t]{2}{*}{$\mathrm{x}$} & $\mathrm{C} 15$ & Unilateral CLP & $\mathrm{v}$ \\
\hline & & & $\mathrm{C} 24$ & Unilateral CLP & $\begin{array}{l}x \\
x\end{array}$ \\
\hline $\mathrm{R} 1$ & Bilateral CLP & v & $\mathrm{C} 2$ & Bilateral CLP & v \\
\hline $\mathrm{R} 4$ & Bilateral CLP & $y$ & $\mathrm{C} 3$ & Bilateral CLP & $\mathrm{x}$ \\
\hline $\mathrm{R} 12$ & Bilateral CLP & $v$ & $\mathrm{C} 22$ & Bilateral CLP & $\mathrm{x}$ \\
\hline R16 & Bilateral CLP & $\begin{array}{l}x \\
x\end{array}$ & & & \\
\hline $\mathrm{R} 10$ & Soft palate cleft & $\mathrm{x}$ & $\mathrm{C} 7$ & Soft palate cleft & $\mathrm{x}$ \\
\hline \multirow{3}{*}{ R19 } & \multirow[t]{3}{*}{ Soft palate cleft } & \multirow[t]{3}{*}{$\mathrm{x}$} & $\mathrm{C} 17$ & Soft palate cleft & $\mathrm{x}$ \\
\hline & & & $\mathrm{C} 21$ & Soft palate cleft & $\mathrm{x}$ \\
\hline & & & $\mathrm{C} 23$ & Soft palate cleft & $\mathrm{x}$ \\
\hline R20 & $\begin{array}{l}\text { Cleft of the hard } \\
\text { and soft palate }\end{array}$ & $\mathrm{x}$ & C18 & $\begin{array}{l}\text { Cleft of the hard } \\
\text { and soft palate }\end{array}$ & $\mathrm{x}$ \\
\hline $\mathrm{R} 25$ & $\begin{array}{l}\text { Cleft of the hard } \\
\text { and soft palate }\end{array}$ & $\mathrm{x}$ & & & \\
\hline
\end{tabular}

CLP, Cleft lip and palate; HIV-E, HIV-exposure

According to Table 1, each group had three participants using feeding obturators. Feeding obturators were supplied at their first visit to the FCDC if participants had uni- or bilateral complete clefts or soft palate and 50\% hard palate clefts. If the participant had a soft and hard palate cleft and fed well with a bottle, or had a narrow cleft, no obturator was provided. Obturators are adjusted regularly to accommodate facial growth. Although a wide range of clefts were present in each group, the type of clefts between the groups were closely matched.

Table 2 shows no significant differences between the two groups for chronological age, gestation age and birth weight, which indicates further equivalence between the two groups. Although not statistically significant, the mean birth weight of the research group (RG) was slightly lower than that of the control group (CG). The majority of participants in both groups were born full term, but breastfeeding was not feasible due to the presence of CLP. All participants were tube fed for at least one day. The RG experienced more problems early on as they had a longer NICU hospitalisation (not statistically significant) and took on average seven days longer before being able to wean off of tube feeding, and achieve successful bottle feeding $(p=0.042)$. 
Table 2 Participant description $(n=25)$

\begin{tabular}{|c|c|c|c|c|c|c|c|c|c|}
\hline \multirow[t]{2}{*}{ Characteristics } & \multicolumn{4}{|c|}{$\begin{array}{c}\text { RG } \\
\begin{array}{c}\text { Infants with unrepaired CLP only and HIV-E } \\
(\mathrm{n}=12)\end{array} \\
\end{array}$} & \multicolumn{4}{|c|}{$\begin{array}{l}\text { CG } \\
\text { Infants with an unrepaired CLP }(n=13)\end{array}$} & \multirow{2}{*}{$\begin{array}{c}\text { p-values } \\
-\end{array}$} \\
\hline & Number & Percentage & - & - & Number & Percentage & - & - & \\
\hline \multirow[t]{2}{*}{ Gender (Male) } & $n=4$ & $33.30 \%$ & - & - & $\mathrm{n}=7$ & $53.80 \%$ & - & - & $0.038^{*}$ \\
\hline & Mean & $\begin{array}{l}\text { Standard } \\
\text { deviation }\end{array}$ & Mode & Range & Mean & $\begin{array}{l}\text { Standard } \\
\text { deviation }\end{array}$ & Mode & Range & - \\
\hline $\begin{array}{l}\text { Chronological } \\
\text { age (days) }\end{array}$ & 47.92 & 29.42 & 31.00 & $8-89$ & 37.00 & 27.91 & 33.00 & $2-89$ & 0.235 \\
\hline $\begin{array}{l}\text { Gestation age } \\
\text { (weeks) }\end{array}$ & 39.50 & 1.73 & 40.00 & $36-42$ & 39.00 & 1.29 & 40.00 & $36-40$ & 0.419 \\
\hline $\begin{array}{l}\text { Birth weight } \\
(\mathrm{kg})\end{array}$ & 2.91 & 0.51 & 2.50 & $\begin{array}{l}2.35- \\
3.80\end{array}$ & 3.29 & 0.57 & 2.94 & $2.40-4.60$ & 0.096 \\
\hline $\begin{array}{l}\text { NICU stay } \\
\text { (days) }\end{array}$ & 11.00 & 9.88 & 14.00 & $1-39$ & 6.4 & 4.94 & 2.00 & $1-14$ & 0.178 \\
\hline $\begin{array}{l}\text { Number of days } \\
\text { before bottle fed } \\
\text { since birth }\end{array}$ & 9,17 & 10.38 & 1.00 & $1-39$ & 2.85 & 2.03 & 1.00 & $1-8$ & $0.042 *$ \\
\hline
\end{tabular}

According to Table 3, all RG mothers were using ART during pregnancy. All RG participants were therefore exposed to HIV and ART during gestation. Six participants did not receive any ART after birth as their HIV status was already confirmed negative, five participants received $\mathrm{NVP}$ and one received (NVP/ZDV). It is known that exposure to ART in utero can have confounding effects on infants, such as oral thrush and increased exposure to co-infections, which could lead to additional feeding difficulties ${ }^{16}$. Receiving ART can also lead to negative side effects related to feeding and swallowing ${ }^{22}$. None of the RG mothers reported that the participants presented with these side effects.

\section{Table 3 Description of participants' mothers $(n=25)$}

\begin{tabular}{ccc}
\hline & Mothers of RG & Mothers of CG \\
\hline Age & - & - \\
Mean & 30.33 & 26.00 \\
Mode & 23.00 & 19.00 \\
Standard deviation & 5.40 & 5.79 \\
Use of ARTs during pregnancy & $100 \%$ & - \\
Starting prior to pregnancy & $(\mathrm{n}=11) 91.70 \%$ & - \\
Starting in first trimester & $(\mathrm{n}=1) 8.30 \%$ & - \\
\hline
\end{tabular}

ARTs, Antiretrovirals

\section{Material}

The Neonatal Feeding Assessment Scale (NFAS), a locally developed tool, was used to observe participants' feeding. The NFAS aims to identify and describe oropharyngeal dysphagia (OPD) in very young infants, and address needs in resource-constrained countries by reducing the need for Modified Barium Swallow studies ${ }^{23}$. The NFAS consists of six sections including observing the infant's physiological status, state of alertness, stress cues, general movement and muscle tone during feeding, an oral peripheral evaluation and a clinical feeding and swallowing evaluation $^{23}$. The oral peripheral evaluation entails observations of the infant's oral reactions, oral structure and function, and cranial nerve function to indicate possible symptoms of $\mathrm{OPD}^{23}$. The clinical feeding and swallowing evaluation includes observations of non-nutritive sucking (NNS), nutritive sucking (NS), and behavioural responses to feeding, and specific symptoms of OPD ${ }^{23}$. Symptoms of OPD may include uncoordinated tongue movements during NNS and NS, poor/weak sucking response, and coughing or gurgling during/after swallowing ${ }^{23}$. Criterion validity and inter-rater reliability of the NFAS was estab- 
lished with very young LBW/PTB infants ${ }^{24}$. The NFAS was supplemented with an objective measure. The effectiveness of participants' oral feeding skills (OFS) was determined by recording the volume of milk prior to feeding, the feeding session duration, the rate of milk transfer per minute, and the total milk volume consumed over the entire feed ${ }^{25}$.

\section{Procedures}

Institutional ethical clearance (protocol \#43/2017; GW20170310HS) was obtained. Potential participants were identified and voluntary informed consent was requested from mothers ( $\geq 18$ years) on behalf of their infants. A pilot study was conducted on the first two participants. As no adjustments were made to the data collection instruments and procedures, the pilot participants were included in the main study. Data were collected prospectively by the first author. Clinic files were reviewed and parents briefly interviewed to obtain relevant demographic information and background history. Prior to the feeding evaluation mothers were guided by the team's nursing professionals on the most appropriate feeding method for their infants. The prosthodontist also evaluated the infant should a feeding plate be required. An oral peripheral evaluation was conducted by the researcher using gloves and an adjustable light. The purpose was to determine the presence or absence of specific oral reflexes and observing the oral structure and function.

The observation of cranial nerve function to indicate possible symptoms of dysfunction such as a weak cry, weak lip seal, facial asymmetry and reduced tongue movements were conducted prior to and during the feeding session. A single bottle-feeding session by the mother during the participant's scheduled appointment at the FCDC was observed. The observation was conducted in a private cubicle, which limited environmental sound. Participants were fed using their own bottles and milk, either formula or expressed breast milk. The researcher used a generalised IOS stopwatch app to determine the duration of the feeding session. The researcher recorded the volume of milk in the bottle prior to the start of feeding to ensure that the correct volume was obtained after completion of the feeding session. The volume of milk consumed, duration of the feeding session and the rate of milk transfer as described by Lau and Smith ${ }^{25}$ were calculated separately to determine the effectiveness of oral feeding in the participants. Some participant's feeds were shorter than five minutes which meant that the combined proficiency could not be measured to determine the level of OFS as intended. The combined proficiency of feeding is the volume of milk taken during the first five minutes divided by the total volume of milk prescribed in millilitres and the rate of milk transfer per minute ${ }^{24}$. The aim of this measurement was therefore to compare the effectiveness of OFS between the RG and CG as described in the results. After completion of the feeding session the outcomes were discussed with parents and recommendations and referrals were made.

\section{Data analysis}

The NFAS is scored using a binary system (YES/NO) for each item in the six sub-sections to navigate clinicians to identify the presence/absence of OPD ${ }^{23}$. All the items of the different sub-sections were scored YES if the signs/symptoms were observed during feeding or $\mathrm{NO}$ if absent. The overall outcome of each sub-section was scored YES if OPD was likely to be present and NO if OPD was not likely to be present. The overall diagnostic outcome of the test is scored YES for OPD likely to be present if a score of three or more was obtained from the different sub-sections. A second rate observed three $(12 \%)$ participants. The two sets of scores were compared to determine inter-rater reliability. A 100\% agreement between the researcher and second rater was found for scoring of the overall outcome of the NFAS. Data were analysed by using the Statistical Package for the Social Sciences (SPSS) and SAS release 9.4 (SAS Institute Inc.). All statistical tests were two-sided and $\mathrm{p} \leq 0.05$ was considered significant. Non-parametric statistical measures were used due to the small sample size and the distribution of data. The Wilcoxon test and Fishers exact test were used to compare participant characteristics, results of the NFAS and OFS between the two groups, and the scores obtained from the two raters to determine inter-rater reliability.

\section{Results}

According to Table 4, there was a statistically significant difference between the number of participants likely to present with OPD and the number not likely to present with OPD, irrespective of the RG or CG. Therefore, the results indicated that participants in the RG were more likely to present with OPD than their HIV-unexposed counterparts.

African Health Sciences Vol 18 Issue 4, December, 2018 
Table 4 Overall outcome of the Neonatal Feeding Assessment Scale

\begin{tabular}{ccccc}
\hline Outcome & $\begin{array}{c}\text { RG } \\
\text { Infants with unrepaired } \\
\text { CLP and HIV-E }(\mathbf{n}=\mathbf{1 2})\end{array}$ & $\begin{array}{c}\text { CG } \\
\text { Infants with } \\
\text { unrepaired CLP } \\
(\mathbf{n}=\mathbf{1 3})\end{array}$ & Total & p-value \\
\hline $\begin{array}{c}\text { Dysphagia likely to } \\
\text { be present }\end{array}$ & $75.00 \%(\mathrm{n}=9)$ & $15.38 \%(\mathrm{n}=2)$ & 11 & \\
$\begin{array}{c}\text { DysphagiaNOT } \\
\text { likely to be present }\end{array}$ & $25.00 \%(\mathrm{n}=3)$ & $84.62 \%(\mathrm{n}=11)$ & 14 & $0.0048^{*}$ \\
\hline Total & 12 & 13 & 25 & \\
\hline
\end{tabular}

A statistically significant difference between the likelihood of dysphagia was obtained in the overall outcome of the NFAS (Table 4), but Table 5 shows sub-sections A - D were not statistically significant different between the two groups. The two groups were therefore mostly similar regarding their physiological sub-systems during feeding. Although no statistically significant difference were found between the states of alertness of the two groups, most of the participants in the CG were in a optimal state of alertness during feeding whereas most of the RG were in a non-optimal state, such as deep- and light sleep, drowsy, alert, agitated or crying. No statistically significant difference was found between the stress cues of the two groups, however, more participants in the RG showed stress cues. These included a panicked or worried look, straining or squirming, and skin colour changes. The majority of participants in both groups presented with normal general movement and muscle tone during feeding, but one participant in the CG and two (16.67\%) in the RG presented with increased stiffness during feeding. Statistically significant differences between the groups were found for sub-sections $\mathrm{E}$ and $\mathrm{F}$, emphasising unique feeding difficulties of the participants in the RG. Specific oral peripheral deviations in section $\mathrm{E}$ were as follows: The majority of participants in both groups did not have a sufficient lip seal or closure at rest or during feeding. All participants had structural deviations of the lip and palate or of the palate only. One RG participant presented with microglossia. Participants with OPD in both groups presented with a cycle of $<10$ sucks per burst for NNS and NS. The following deviations were observed in section F: The RG with OPD did not show transverse tongue reactions or a rooting response, showed delayed initiation of sucking, uncoordinated tongue movements, and gurgling during feeding, whereas the CG participants did not show any of these symptoms. Table 6 depicts a comparison of the effectiveness of the OFS calculated during the feeding session. 
Table 5 Outcomes of the sub-sections of the Neonatal Feeding Assessment Scale

\begin{tabular}{|c|c|c|c|c|}
\hline Sub-sections & Outcome & $\begin{array}{c}\text { Infants with } \\
\text { unrepaired CLP } \\
\text { and HIV-E }(n=12)\end{array}$ & $\begin{array}{c}\text { Infants with } \\
\text { unrepaired CLP } \\
\text { only }(n=13)\end{array}$ & p-values \\
\hline \multirow{2}{*}{$\begin{array}{c}\text { Section A: } \\
\text { Functioning of } \\
\text { physiological } \\
\text { subsystems }\end{array}$} & $\begin{array}{c}\text { Dysphagia likely to } \\
\text { be present }\end{array}$ & $25.0 \%(n=3)$ & $23.1 \%(n=3)$ & \multirow{2}{*}{0.248} \\
\hline & $\begin{array}{l}\text { Dysphagia NOT } \\
\text { likely to be present }\end{array}$ & $75.0 \%(\mathrm{n}=9)$ & $76.9 \%(\mathrm{n}=10)$ & \\
\hline \multirow[t]{2}{*}{$\begin{array}{c}\text { Section B: State of } \\
\text { alertness }\end{array}$} & $\begin{array}{l}\text { Optimal state of } \\
\text { alertness }\end{array}$ & $41.7 \%(n=5)$ & $46.2 \%(n=6)$ & \multirow[t]{2}{*}{0.4147} \\
\hline & $\begin{array}{c}\text { Non-optimal state of } \\
\text { alertness }\end{array}$ & $58.3 \%(n=7)$ & $53.8 \%(n=7)$ & \\
\hline \multirow[t]{2}{*}{$\begin{array}{l}\text { Total outcome of } \\
\text { section A \& B }\end{array}$} & $\begin{array}{c}\text { Dysphagia likely to } \\
\text { be present }\end{array}$ & $16.7 \%(n=2)$ & $15.4 \%(n=2)$ & \multirow[b]{2}{*}{0.488} \\
\hline & $\begin{array}{l}\text { Dysphagia NOT } \\
\text { likely to be present }\end{array}$ & $83.3 \%(\mathrm{n}=10)$ & $84.6(n=11)$ & \\
\hline \multirow[t]{2}{*}{$\begin{array}{c}\text { Section C: Stress } \\
\text { cues }\end{array}$} & $\begin{array}{c}\text { Dysphagia likely to } \\
\text { be present }\end{array}$ & $66.7 \%(n=8)$ & $30.8 \%(n=4)$ & \multirow[b]{2}{*}{0.115} \\
\hline & $\begin{array}{l}\text { Dysphagia NOT } \\
\text { likely to be present }\end{array}$ & $33.3 \%(n=4)$ & $69.2 \%(n=9)$ & \\
\hline \multirow{2}{*}{$\begin{array}{c}\text { Section D: General } \\
\text { movement and } \\
\text { muscle tone at rest } \\
\text { and }\end{array}$} & $\begin{array}{c}\text { Dysphagia likely to } \\
\text { be present }\end{array}$ & $16.7 \%(n=2)$ & $7.7 \%(n=1)$ & \multirow[t]{2}{*}{0.564} \\
\hline & $\begin{array}{l}\text { Dysphagia NOT } \\
\text { likely to be present }\end{array}$ & $83.3 \%(n=10)$ & $92.3 \%(n=12)$ & \\
\hline \multirow{2}{*}{$\begin{array}{l}\text { Section E: Oral } \\
\text { peripheral } \\
\text { evaluation }\end{array}$} & $\begin{array}{c}\text { Dysphagia likely to } \\
\text { be present }\end{array}$ & $91.7 \%(n=11)$ & $46.2 \%(n=6)$ & \multirow[t]{2}{*}{$0.025^{*}$} \\
\hline & $\begin{array}{l}\text { Dysphagia NOT } \\
\text { likely to be present }\end{array}$ & $8.3 \%(\mathrm{n}=1)$ & $53.8 \%(n=7)$ & \\
\hline \multirow{2}{*}{$\begin{array}{c}\text { Section F: Clinical } \\
\text { feeding and } \\
\text { swallowing } \\
\text { evaluation }\end{array}$} & $\begin{array}{l}\text { Dysphagia likely to } \\
\text { be present }\end{array}$ & $91.7 \%(n=11)$ & $30.8 \%(n=4)$ & \multirow[t]{2}{*}{$0.008^{*}$} \\
\hline & $\begin{array}{l}\text { Dysphagia NOT } \\
\text { likely to be present }\end{array}$ & $8.3 \%(n=1)$ & $69.2 \%(n=9)$ & \\
\hline
\end{tabular}

Table 6 shows that the RG mothers presented more milk to the infant prior to the feeding session. No clarification can be offered for the increased milk volume, as the groups did not differ in age, and therefore required the same volume of milk. In approximately the same time, participants in the RG had a smaller intake of milk compared to the CG. The RG were most likely to present with OPD and consumed the least amount of milk. Par- ticipants in the RG most likely to present with OPD as indicated by the NFAS, also consumed the least amount of milk as determined by the effectiveness of OFS, as compared to the CG. It therefore appears that participants identified with OPD on the NFAS were also the same participants with least effective OFS. The results of the two measuring instruments therefore appear to supplemt one another, thereby increasing the reliability of the findings. 
Table 6 Comparison of the effectiveness of oral feeding skills between the two groups

\begin{tabular}{|c|c|c|c|c|c|c|c|}
\hline \multirow[b]{2}{*}{ OFS } & \multicolumn{3}{|c|}{$\begin{array}{c}\text { Infants with unrepaired CLP only and } \\
\text { HIV-E }(n=12)\end{array}$} & \multicolumn{3}{|c|}{$\begin{array}{l}\text { Infants with an unrepaired CLP } \\
(\mathrm{n}=13)\end{array}$} & \multirow{2}{*}{$\begin{array}{l}\text { p-values } \\
\text { p-values }\end{array}$} \\
\hline & Mean & $\begin{array}{l}\text { Standard } \\
\text { deviation }\end{array}$ & Range & Mean & $\begin{array}{l}\text { Standard } \\
\text { deviation }\end{array}$ & Range & \\
\hline $\begin{array}{l}\text { Volume of milk } \\
\text { presented by } \\
\text { the mother } \\
\text { prior to the } \\
\text { feeding session } \\
\text { (ml) }\end{array}$ & 165.42 & 74.15 & $50-260$ & 95.54 & 50.58 & $\begin{array}{l}30.00- \\
200.00\end{array}$ & $0.022 *$ \\
\hline $\begin{array}{l}\text { Duration of } \\
\text { feeding } \\
\text { (minutes) }\end{array}$ & 7.89 & 6.70 & $\begin{array}{l}2.25- \\
25.00\end{array}$ & 7.96 & 6.24 & $\begin{array}{l}1.43- \\
25.00\end{array}$ & 0.765 \\
\hline $\begin{array}{c}\text { Rate of milk } \\
\text { transfer/minute } \\
\text { (ml) }\end{array}$ & 4.80 & 7.05 & $\begin{array}{l}1.42- \\
26.67\end{array}$ & 7.97 & 8.50 & $\begin{array}{l}2.00- \\
34.96\end{array}$ & $0.0133^{*}$ \\
\hline $\begin{array}{c}\text { Total milk } \\
\text { volume } \\
\text { consumed } \\
\text { during the } \\
\text { entire feed (ml) }\end{array}$ & 24.00 & 16.91 & $\begin{array}{l}5.00- \\
60.00\end{array}$ & 41.08 & 18.98 & $\begin{array}{l}15.00- \\
80.00\end{array}$ & $0.025^{*}$ \\
\hline
\end{tabular}

$\mathrm{ml}$, millilitres

\section{Discussion}

The purpose of this study was to investigate whether differences exist between the feeding characteristics of infants with unrepaired CLP and HIV-E compared to infants with unrepaired CLP only. The type of cleft the participants presented with and the use of feeding obturators were matched. A different variety of clefts were present in each group. On average the groups were similar in age, gestation age and birth weight, which are factors known to influence feeding ${ }^{26}$. Confounding factors contributing to a biased distribution of feeding difficulties between the two groups were therefore limited.

A clear difference was found between the overall outcome of the presence of OPD in the RG and CG. OPD was expected in both groups as they all have an unrepaired CLP, however, more participants in the RG presented with OPD compared to the CG. Participants with OPD in both groups presented with inadequate or weak lip seal and $<10$ sucks per burst before pausing during the NNS and NS. This was expected as infants with unrepaired CLP are known to have difficulties with nipple compression and to generate sufficient negative intraoral pressure during sucking ${ }^{12,13,14}$. As expected and also described in the CLP literature, all participants in this study were bottle fed as breastfeeding was not possible ${ }^{13,14}$. Additional feeding difficulties, not associated with unrepaired CLP and not detected in the CG, were observed in RG participants with OPD. Participants with OPD in the RG did not display rooting responses, or transverse tongue reactions, and showed uncoordinated tongue movements and delayed sucking initiation. HIV-positive infants are known to present with weak or uncoordinated tongue movements ${ }^{15}$. Delayed initiation of sucking is associated with an absence of rooting and uncoordinated tongue movements ${ }^{27}$. The rooting response and transverse tongue reaction are both reflexes important during the normal process of feeding and swallowing in very young infants ${ }^{27}$. The hypoglossal nerve, involved in the regulation of coordinated tongue movements, plays an integral part in oral feeding ${ }^{27,28}$. In addition, the length of NICU stay and subsequent increased non-oral feeding in some of the RG participants could also have contributed to the absence of a rooting response and uncoordinated tongue movements. The presence or absence of specific oral reflexes facilitated by the cranial nerves could be 
indicative of an infant's neurological stability ${ }^{29}$. Normal sucking, swallowing, and respiratory functions are controlled by the central pattern generators in the brain ${ }^{30}$. It is assumed that NS will be sufficient when the maturity levels of these central pattern generators are adequate ${ }^{31}$. It therefore appears that the feeding difficulties of the RG with OPD were not only as a result of structural abnormalities, but showed symptoms of possible neurological involvement.

Safe and successful bolus transportation relies on the timely synchronization of sucking ${ }^{31}$. Therefore, due to delayed initiation and poor synchronization of sucking, the rate of milk transfer per minute and the total volume of milk consumed by the RG with OPD were less. Agreement between the results of the two measuring tools were therefore found.

In contrast to other studies of young infants with HIV-E ${ }^{7,32,33}$, no cases of pneumonia or pneumocystis jiroveci pneumonia (PJP) or any cardiac defects were found in the RG. The nature of the clinic could have had an impact on this, as the FCDC is an out-patient clinic and infants with pneumonia, PJP or cardiac defects would most likely have been in-patients.

The extended tube feeding duration and prolonged NICUstay found in the RG were the first signs of differences between the study groups and may therefore be viewed as predictive risks in the early identification of OPD in infants with HIV-E and CLP. Feeding is a complex process and the ability to feed successfully from birth has an effect on caregiver-infant attachment, which is essential to an infant's development ${ }^{27}$. Feeding and swallowing difficulties can have serious impacts on weight gain, growth, and development ${ }^{34}$. Early identification and intervention of OPD in infants with CLP and HIV-E is essential.

\section{Conclusion}

In comparison with the few CG participants identified with OPD, the RG presented with unique symptoms of OPD and difficulties with OFS. Participants in the RG were not infected with HIV at the time of data collection, but were exposed to HIV and ART in utero and some after birth as well. It appears that participants with unrepaired CLP, HIV-E and OPD presented with a unique feeding profile, suggesting possible neurological involvement in the symptoms of their feeding difficulties. At this stage there is no known study isolating the feeding difficulties of infants with unrepaired CLP and HIV-E. The sample size of the study was small, but is expected as this population may never be available in large numbers. Since larger sample sizes are unlikely to be found in the population of infants with unrepaired CLP and HIV-E, more studies using other measuring tools for feeding are required to confirm the results and increase the evidence of the present study. The results of this exploratory study confirm the tentative alternative hypothesis that there were significant differences between the feeding of the RG and CG.

\section{Competing interests}

The authors declare that they have no financial or personal competing interests that may have influenced them in writing this article.

\section{References}

1. Wudineh F, Damtew B. Mother-to-child transmission of HIV infection and its determinants among exposed infants on care and follow-up in Dire Dawa city, Eastern Ethiopia. AIDS Res Treat. 2016; 2016:1-6. http://dx.doi. org//10.1155/2016/3262746

2. UNAIDS. UNAIDS data 2017. Retrieved from http://www.unaids.org/sites/default/files/media_asset/20170720_Data_book_2017_en.pdf. (2017).

3. Adam S. HIV and pregnancy. O \& G Forum 2015; 25:19-22.

4. World Health Organization (WHO), United Nations Children's Fund. Guideline: updates on HIV and infant feeding: the duration of breastfeeding, and support from health services to improve feeding practices among mother living with HIV. Geneva: WHO; 2016.

5. WHO. Consolidated guidelines on the use of antiretroviral drugs for treating and preventing HIV infection: Recommendations for a public health approach, $2^{\text {nd }} e d$. Geneva: WHO; 2016.

6. Bisto F, Nicco E, Calzi A, Glacobbe DR, Mesini A, Banguissa $\mathrm{H}$ et al. Pregnancy outcomes following exposure to efavirenz-based anti-retroviral therapy in the Republic of Congo. New Microbiol. 2015; 38:185-192.

7. Evans C, Jones CE, Prendergast AJ. HIV-exposed, uninfected infants: New global challenges in the era of paediatric HIV elimination. Lancet. 2016; 16:92-107. http:/ / dx.doi.org/10.1016/S1473-3099(16)00055-4 
8. Sugandhi N, Rodrigues J, Kim M, Ahmed S, Amzel A, Tolle $\mathrm{M}$ et al. HIV-exposed infants: Rethinking care for a lifelong condition. AIDS. 2013; 27 Suppl 2:S187-95. http://dx.doi.org//10.1097/QAD.0000000000000090.

9. Le Doaré K, Bland R, Newell ML. Neurodevelopment in children born to HIV-infected mothers by infection and treatment status. Pediatrics. 2012; 130(5):1-19. http:// dx.doi.org/10.1542/peds.2012-0405

10. Brackis-Cott E, Kang E, Dolezal C, Abrams EJ, Mellins CA. The impact of perinatal HIV infection on older school- aged children's and adolescents' receptive language and word recognition skills. AIDS Patient Care STDS. 2009, 23(6),415-421.

11. Uthman OA, Nachega JB, Anderson J, Kanters S, Mills EJ, Renaud, $R$ et al. Timing of initiation of antiretroviral therapy and adverse pregnancy outcomes: A systematic review and meta-analysis. Lancet HIV. 2017; 4:2130. http://dx.doi.org/10.1016/

S2352-3018(16)30195-3

12. Kummer AW. Cleft palate and craniofacial anomalies: Effects on speech and resonance, 3rd ed. USA: Cengage Learning; 2014; 351-380.

13. Zajac DJ, Vallino LD. Evaluation and management of cleft lip and palate: A developmental perspective. California: Plural Publishing, Inc.; 2017; 23-47.

14. Gupta R, Luthra RP, Sharma A. A feeding appliance for a newborn baby with cleft lip and palate. Int $J$ Res Health Allied Sci. 2015; 1(1):25-27.

15. Pressman H. Dysphagia and related assessment and management in children with HIV/AIDS. In: Swanepoel DW, Louw B. HIV/AIDS: Related communication, hearing and swallowing disorders. USA: Plural Publishing, 2010; 351-381.

16. Evans C, Humphrey JH, Ntozini R, Prendergast AJ. HIV-exposed uninfected infants in Zimbabwe: Insights into health outcomes in the pre-antiretroviral therapy era. Front Immunol. 2016; 7:190. http://dx.doi.org/ 10.3389/ fimmu.2016.00190

17. Mandelbrot L, Sibiude J. A link between antiretrovirals and perinatal outcomes. Lancet. 2017; published online Nov 16. http://dx.doi.org/10.1016/S23523018(16)30188-6

18. Hendricks MK, Eley B, Bourne LT. Nutrition and HIV/AIDS in infants and children in South Africa: Implications for food-based dietary guidelines. Matern Child Nutr. 2007; 3:322-333.
19. Bütow KW, Van Wyk PJ. Difference in the clinical appearance of white versus black patients with facial cleft deformities: A retrospective study. SADJ. 2007; 62:298304.

20. Bütow KW. Treatment of facial cleft deformities: An illustrated guide. Tokyo: Ishiyaku EuroAmerica, Inc, 1995.

21. Leedy PD, Ormrod JE. Practical research: Planning and design, International edition. USA: Pearson Education Limited, 2014.

22. Lipman MCI, Baker RW, Johnson MA. An atlas of differential diagnosis in HIV disease, $2^{\text {nd }}$ ed. New York: Parthenon, 2004.

23. Viviers M, Kritzinger A, Vinck B. Development of a clinical feeding assessment scale for very young infants in South Africa. SAJCD 2016; 63(1):1-11. http://dx.doi. org/10.4102/sajcd.v63i1.148

24. Viviers M, Kritzinger A, Vinck B, Graham M. Preliminary psychometric performance of the neonatal feeding assessment scale. SAJCD. 2017, 64(1),1-8. http://dx.doi. org/10.4102/sajcd.v64i1.163

25. Lau C, Smith EO. A novel approach to assess oral feeding skills of preterm infants. Neonatology. 100,64-70. http://dx.doi.org/10.1159/000321987

26. Jadcherla S. (2016). Dysphagia in the high-risk infant: Potential factors and mechanisms. Am J Clin Nutr. 2016;103(2):622 PubMed S-6288S.

27. Arvedson JC, Brodsky L. Paediatric swallowing and feeding: Assessment and management. Canada: Singular Publishing, 2002.

28. Delaney AL, Arvedson JC. Development of swallowing and feeding: Prenatal through first year of life. Dev Disabil Res Rev. 2008; 14:105-117. http://dx.doi. org/10.1002/ddrr.16

29. Hall KD. Pediatric dysphagia: Resource guide. Canada: Singular Thomson Learning, 2001.

30. Amaizu N, Shulman R, Schanler R, Lau C. Maturation of oral feeding skills in preterm infants. Acta Paediatr. 2008; 97:61-67 PubMed .

31. Lau C. Development of infant oral feeding skills: What do we know? Am J Clin Nutr. 2016; 103(Suppl):616S-621S. http://dx.doi.org/10.3945/ajcn.115.109603

32. Mofenson LM, Oleske J, Serchuck L, Van Dyke R, Wilfert C. Treating opportunistic infections among HIV-exposed and infected children: Recommendation from CDC, the National institutes of health, and the In- 
fectious diseases society of America. CID. 2005;40:S1S84.

33. Lipschultz SE, Shearer WT, Thompson B, et al. Cardiac effects of antiretroviral therapy in HIV-negative infants born to HIV-positive mothers. J Am Coll Car- diol. 2011; 57(1):76-85. http://dx.doi.org/10.1016/j. jacc.2010.08.620

34. Dodrill P, Gosa MM. Pediatric dysphagia: Physiology, assessment, and management. Ann Nutr Metab. 2015;66(Suppl 5):24-31. http://dx.doi.org/ 10.1159/000381372 